\title{
A REUTILIZAÇÃo DA GARRAFA PET PARA CONFECÇÃO DE FOGUETE NO ENSINO DA FÍSICA/ QUÍMICA
}

\section{${ }^{* 1}$ Dânlei de Oliveira Preato, ${ }^{2}$ Roseli Maria de Jesus Soares and ${ }^{3}$ Queila Barbosa Alves Druzian}

${ }^{1}$ Especialista em Docência no Ensino Superior, Faculdade de Pimenta Bueno - FAP, Jaru - RO, Brasil; 2Especialista em Didática do Ensino Superior, Faculdade de Ciências Biomédicas de Cacoal - FACIMED, Cacoal RO, Brasil; ${ }^{3}$ Mestranda em Ensino de Ciências da Natureza, Unir-Universidade Federal de Rondônia, Cacoal RO, Brasil

\section{ARTICLE INFO}

Article History:

Received $20^{\text {th }}$ March, 2020

Received in revised form

$22^{\text {nd }}$ April, 2020

Accepted $08^{\text {th }}$ May, 2020

Published online $30^{\text {th }}$ June, 2020

\section{Key Words}

Reação Química, Experimentação,

Leis de Newton.

*Corresponding author:

Dânlei de Oliveira Preato,

\begin{abstract}
The present Project developed at Escola Família Agrícola Dom Antonio Possamai - EFADAP, aims to report the experimental activities, with the Mathematics teacher together with high school students, thus building rockets using a PET bottle in the study of concepts from physics, mathematics and chemistry, aiming to bring students closer to experimental activities, showing at the same time, the combination of theory and practice, where they would have autonomy to elaborate and test their hypotheses about the chemical reaction used in the rocket. The experiment is proposed to students and the teacher is a mediator of the process of study and application of knowledge, organizing weekly classes, until the end of the project. In the final considerations, the steps that students used to develop the experiment during classes are presented as a result of the development of the activity.
\end{abstract}

Copyright (C) 2020, Dânlei de Oliveira Preato et al. This is an open access article distributed under the Creative Commons Attribution License, which permits unrestricted use, distribution, and reproduction in any medium, provided the original work is properly cited.

Citation: Dânlei de Oliveira Preato, Roseli Maria de Jesus Soares and Queila Barbosa Alves Druzian. "A reutilização da garrafa pet para confecção de foguete no ensino da física/ química”, International Journal of Development Research, 10, (06), 37318-37324.

\section{INTRODUCTION}

De acordo com a terceira lei de Newton, na qual descreve, que dois corpos quando se interagem entre si, resultam em um par de forças, isto é, a ação que um corpo exerce sobre outro. Tais forças são denominadas de Ação - Reação. Este é o principal princípio que rege no lançamento de foguetes. Foguetes são máquinas que produzem a força ou o impulso necessário para empurrar um objeto para frente. Seus motores vêm sendo utilizados em voos espaciais, nos quais sua grande potência e capacidade de operar no vácuo são essenciais, mas também podem ser empregados para movimentar mísseis, aeroplanos e automóveis. Nesta concepção, a construção de um foguete de garrafa PET tem como objetivo a demonstração de alguns conceitos físicos e químicos estudados principalmente na disciplina de Física como: Impulso, quantidade de movimento, leis de Newton, aceleração dos corpos, etc., e da Química, principalmente a parte referente a reações químicas. $\mathrm{O}$ projeto teve como intuito contribuir para suprir a necessidade de trabalhar atividades experimentais de Física com alunos do $1^{\circ}$ ano do ensino médio, pois se mostra como uma atividade motivadora que proporciona aos alunos uma maneira diferente para trabalhar alguns conceitos de Física e Química, como demonstrar na prática a teoria das Leis de Newton. Os experimentos podem contribuir para a construção de um ambiente motivador, agradável e rico em situações novas e desafiadoras que, quando bem adaptadas, aumentam as chances de que sejam elaborados conhecimentos e adquiridas habilidades, atitudes e competências relacionadas ao fazer e entender Ciência (ABIB; ARAÚJO, 2003). "O trabalho experimental tem uma reconhecida importância na aprendizagem de Ciências, largamente aceita entre a comunidade científica e pelos professores como metodologia de ensino" (SARAIVA-NEVES; CABALLERO; MOREIRA, 2006).

Fundamentação Teórica: $\mathrm{O}$ foguete de garrafa PET aborda uma grande quantidade de fenômenos relacionados a área de ciências da natureza e matemática e suas tecnologias, e assim, 
permitindo a interação entre as disciplinas da Física e da Química. Tendo como princípio físico do projeto a Dinâmica, abordando e descrevendo as três leis de Newton, sendo a que fundamenta o funcionamento do motor do foguete é a Terceira Lei de Newton, lei da ação e reação, que diz que "a cada ação, sempre se opõe uma reação igual, ou seja, as ações mútuas de dois corpos, um sobre o outro, são sempre iguais e dirigidas para partes contrárias" (RESNICK \& HALLIDAY, 1984). Imaginemos um compartimento fechado onde exista um gás em combustão. A queima do gás irá produzir pressão em todas as direções. O compartimento não se moverá em nenhuma direção, pois as forças nas paredes opostas da câmara irão se anular. Se implantarmos um bocal na parte de baixo deste compartimento, onde os gases possam escapar isso irá acarretar em um desequilíbrio. A pressão exercida nas paredes laterais opostas continuará não produzindo força, pois a pressão de um lado anulará a do outro. Já a pressão exercida na parte superior do compartimento produzirá empuxo, pois não há pressão no lado de baixo (onde está o bocal). Assim, o foguete se deslocará para cima por reação à pressão exercida pelos gases em combustão no compartimento de combustão do motor. Por isto este tipo de motor é chamado de propulsão por reação. Como no espaço exterior não há oxigênio para queimar com o combustível, o foguete deve levar armazenado em tanques não só o combustível, mas também o comburente. A força do empuxo produzido, expressão que determina a força produzida pelo motor de foguete, depende da massa e da velocidade dos gases expelidos pelo bocal. Logo, quanto maior a pressão dos gases expelidos, maior o empuxo.

A equação abaixo representa a reação que ocorre no interior do foguete antes do lançamento.

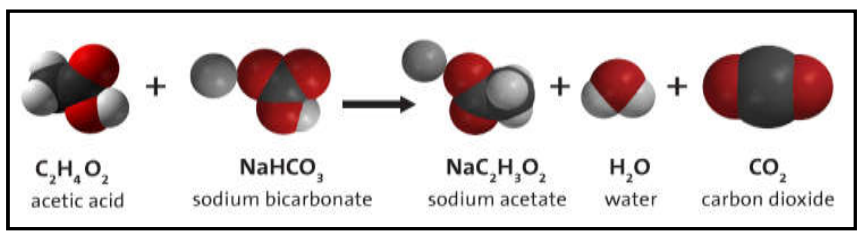

Fonte: American Chemical Society, 2018.

Segundo a reação, a solução aquosa de ácido etanóico (vinagre) reage com bicarbonato de sódio sólido para formar etanoato de sódio aquoso, água liquida e dióxido de carbono gasoso. O dióxido de carbono é o responsável pela elevação da pressão no interior do foguete e, ao ser liberada da trava de segurança do lançador o impulsiona no sentido contrário ao seu sentido de escape, conforme previsto pela lei da açãoreação de Newton. Tudo se inicia com a reação química que ocorre entre o vinagre (ácido etanóico) e o bicarbonato de sódio, é introduzido no interior da base $1000 \mathrm{~mL}$ de vinagre na parte abaixo do registro após inserir o vinagre no interior da base fecha o registro, e coloca $150 \mathrm{~g}$ de bicarbonato de sódio dissolvido em $200 \mathrm{~mL}$ de água na parte acima do registro. Quando o registro é aberto acontece uma reação, na qual libera CO2 (gás carbônico) com um progressivo aumento da pressão no interior da garrafa. Ao final da reação quando todo bicarbonato de sódio se reagir com o vinagre, será destravada a trava de segurança da base que prende o foguete a base, e assim o foguete será lançado. Quando isso ocorrer, a água e o ar são violentamente expulsos (ação) e empurrando (reação) a garrafa na mesma direção e sentido oposto. Além de utilizar o vinagre (ácido etanóico) e o bicarbonato de sódio como combustível do foguete, foi utilizado um segundo tipo de combustível, água e ar comprimido. O processo é simples, a água $(250 \mathrm{~mL})$ é introduzida na garrafa antes de transportá-la para a base, logo após inicia-se a pressurização (bomba de ar manual) e quando a pressão for a desejada libera-se a trava de segurança, permitindo que o foguete tenha a mobilidade para se deslocar. Como o ar comprimido da garrafa tende a igualarse a pressão atmosférica, esta empurra a água pela boca da mesma, movimentando-a em sentido oposto. Também se trata da Terceira Lei de Newton (ação e reação).

\section{METODOLOGIA}

O projeto foi desenvolvido através da construção de projétil, onde se demonstrou a possibilidade de lançamento de um foguete construído com garrafas PET de dois litros pela propulsão produzida pela reação química bicarbonato de sódio e vinagre, e água e ar comprimido, com os seguintes ângulos $45^{\circ}, 60^{\circ}, 75^{\circ}$ e $85^{\circ}$. Utilizou-se basicamente, garrafas PET, materiais e equipamentos de baixo custo, tais como braçadeiras de plástico, canos de PVC, vinagre e bicarbonato de sódio. Às duas garrafas PET são os principais itens do foguete, pois serão utilizadas para a confecção da sua fuselagem, que é composta pelo compartimento de combustão (que chamaremos de compartimento de compressão) e pelo nariz, região frontal do foguete. Para o compartimento de compressão utilizou-se uma garrafa inteira sem alterações. Esta é a parte do foguete que será introduzido seu combustível. Para o nariz, utilizou-se apenas a parte de cima da garrafa, cônica. Essa peça tem a função de minimizar o atrito do ar durante o vôo do foguete, fornecendo ao mesmo um formato mais aerodinâmico. Em seguida, é fixada a parte cônica no fundo da outra garrafa inteira com fita adesiva. É importante que se tenha um bom alinhamento entre estas partes para que não haja maiores complicações durante o vôo. O próximo passo é a construção das aletas do foguete. Elas são fundamentais para sua estabilidade durante o voo. Recorta-se 4 aletas no formato de um triângulo retângulo, tendo seus catetos medindo, 8 e $15 \mathrm{Cm}$, de modo que elas se encaixem na parte cilíndrica da garrafa inteira. O formato das aletas é arbitrário, mas será utilizado o triângulo retângulo por conter somente reto e ser mais fácil de manipular durante o corte, será utilizado o papelão para a confecção das aletas. Com relação a base, foi confeccionado 4 bases cujo lançamento é feito com "ar comprimido". Outra base foi confeccionada na qual tem seu lançamento se baseado na reação química do Bicarbonato de Sódio e Ácido Etanóico, na qual em contato liberam gás carbônico. Os ângulos das bases que serão confeccionados será o ângulo de $45^{\circ}, 60^{\circ}$ e $85^{\circ}$ portanto cada base terá um ângulo diferente. Para a confecção de uma única base na qual tem como seu combustível o "ar comprimido" será utilizado os seguintes itens:

\section{Material utilizado:}

- 3 Canos PVC $20 \mathrm{~mm}, 20 \mathrm{~cm}$ cada um;

- 2 Canos PVC $20 \mathrm{~mm}, 10 \mathrm{~cm}$ cada um;

- 2 Caps para cano $20 \mathrm{~mm}$;

- $1 \mathrm{~T}$;

- 2 Joelhos;

- 4 Braçadeira de plástico;

- 1 Braçadeira de metal, 2 cm de diâmetro;

- 1 Bico de pneu de bicicleta;

- Esparadrapo;

- 1 Bexiga;

- 1 Cola de cano PVC;

- 1 Cano PVC branco 40 mm, $3 \mathrm{~cm}$; 
- Barbante;

- 1 Transferidor;

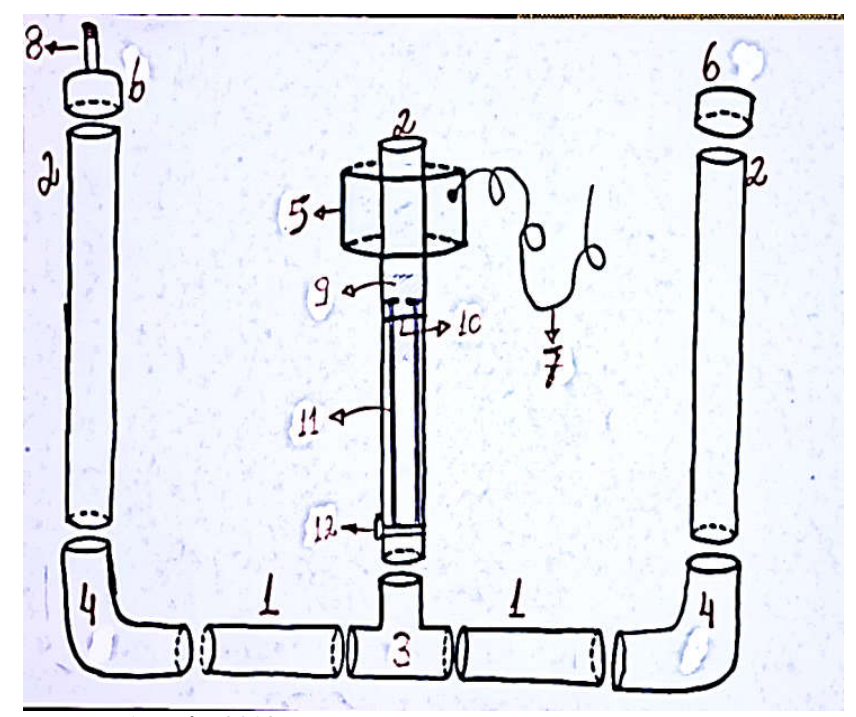

Fonte: Autoria, 2018.

Figura 1. Esquema de montagem da base "ar comprimido

\section{Legenda:}

- $\quad$ Cano PVC $20 \mathrm{~mm}, 10 \mathrm{~cm}$;

- Cano PVC $20 \mathrm{~mm}, 20 \mathrm{~cm}$;

- T $20 \mathrm{~mm}$;

- Joelho $20 \mathrm{~mm}$;

- Cano PVC branco $40 \mathrm{~mm}, 3 \mathrm{~cm}$;

- $\quad$ Caps $20 \mathrm{~mm}$;

- Barbante;

- Bico de pneu de bicicleta;

- Esparadrapo;

- Bico de Bexiga;

- Braçadeira de nylon;

- $\quad$ Braçadeira de metal, $2 \mathrm{~cm}$ de diâmetro.

Obs.: O transferidor foi utilizado para medir os ângulos da base $\left(60^{\circ} \mathrm{e} 85^{\circ}\right)$. Para a confecção da base reação química com ângulo de $45^{\circ}$, na qual tem como seu combustível o "Bicarbonato de Sódio e Ácido Etanóico" serão utilizados os seguintes itens:

\section{Material utilizado}

- 2 Canos PVC $50 \mathrm{~mm}, 22 \mathrm{~cm}$;

- 3 Canos PVC $50 \mathrm{~mm}, 15 \mathrm{~cm}$;

- 1 Cano PVC $20 \mathrm{~mm}, 15 \mathrm{~cm}$;

- 2 Caps PVC $50 \mathrm{~mm}$;

- 2 Joelho PVC $90^{\circ} 50 \mathrm{~mm}$;

- 1 T PVC $50 \mathrm{~mm}$;

- 1 Registro PVC $50 \mathrm{~mm}$;

- 1 Luva Soldável $50 \mathrm{~mm}$;

- 1 Bucha de Redução Longa Marrom PVC Soldável $50 \times 20 \mathrm{~mm}$;

- 6 Braçadeira de nylon;

- 1 Braçadeira de metal, 2 cm de diâmetro;

- Esparadrapo;

- Bico de Bexiga;

- Cano PVC branco $40 \mathrm{~mm}, 3 \mathrm{~cm}$;

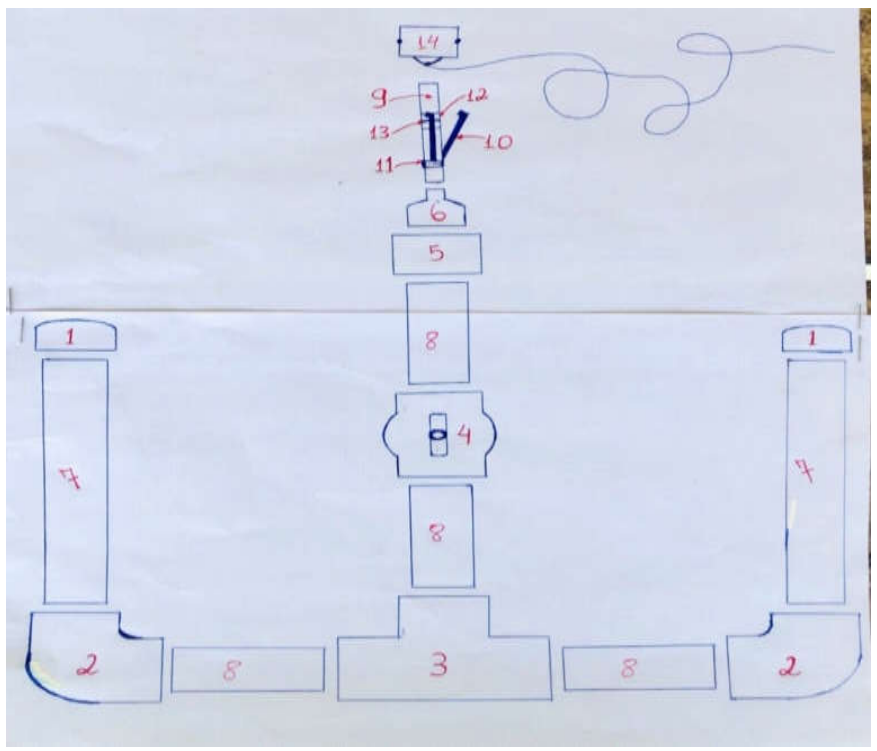

Fonte: Autoria, 2018.

Figura 2. Esquema de montagem da base "Reação Química"

Legenda:

- $\quad$ Caps $50 \mathrm{~mm}$;

- Joelho $50 \mathrm{~mm}$;

- T $50 \mathrm{~mm}$;

- Registro $50 \mathrm{~mm}$;

- Luva Soldável $50 \mathrm{~mm}$;

- Bucha de Redução Longa Marrom PVC Soldável 50x20 mm;

- $\quad$ Cano PVC $50 \mathrm{~mm}, 22 \mathrm{~cm}$;

- Cano PVC $50 \mathrm{~mm}, 15 \mathrm{~cm}$;

- Cano PVC $20 \mathrm{~mm}, 15 \mathrm{~cm}$;

- Braçadeira de nylon;

- Braçadeira de metal, $2 \mathrm{~cm}$ de diâmetro;

- Esparadrapo;

- Bico de Bexiga;

- Cano PVC branco $40 \mathrm{~mm}, 3 \mathrm{~cm}$;

Obs.: O transferidor foi utilizado para medir o ângulo da base $\left(45^{\circ}\right)$.

As atividades experimentais sempre estiveram presentes no processo de ensino aprendizagem, contribuindo para o ensino das ciências, em geral. Em particular, os professores de física demonstram uma preocupação maior com esta metodologia, devido os alunos em geral terem uma maior resistência à disciplina, porem gostam da demonstração da teoria na prática. Segundo Seré, (2003, p.39), diz que a atividade experimental vem associar a teoria com práticas, pois nos relata, como isso ocorre:

Graças às atividades experimentais, o aluno é incitado a não permanecer no mundo dos conceitos e no mundo das 'linguagens', tendo a oportunidade de relacionar esses dois mundos com o mundo empírico. Compreende-se, então, como as atividades experimentais são enriquecedoras para o aluno, uma vez que elas dão um verdadeiro sentido ao mundo abstrato e formal das linguagens. (SERÉ, 2003, p. 39). 


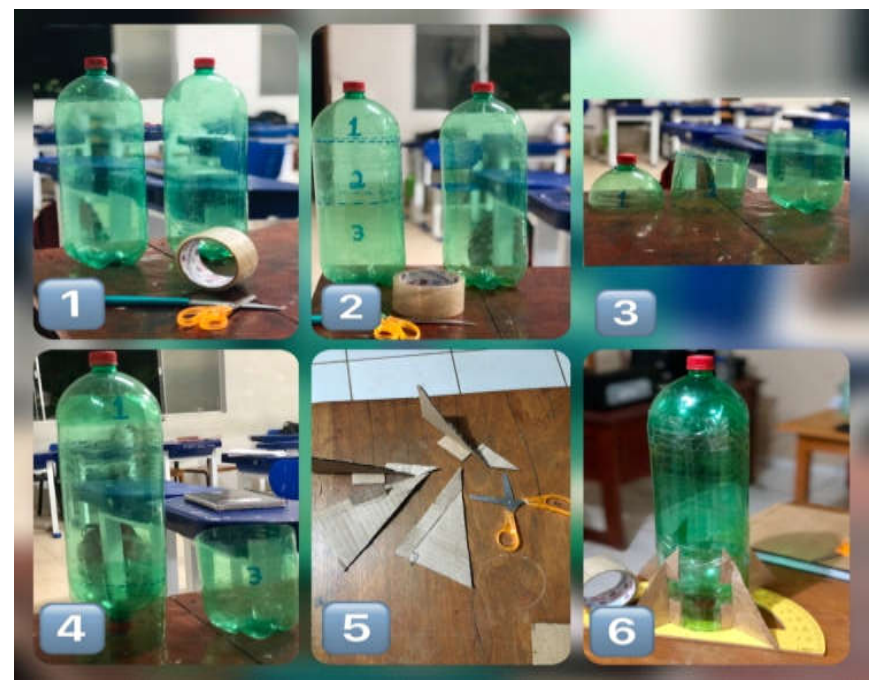

Fonte: Autoria, 2019.

Figura 3. Esquema de montagem do foguete

Legenda:

- Para confecção do foguete será utilizado 2 garrafas PET's de 2 , na figura 1 temos 2 garrafas PET's, tesoura, uma faca de serra e uma fita adesiva;

- $\quad$ Na figura 2, temos 2 garrafas PET's, porem demarcamos uma com a ajuda de um pincel atômico, na qual usaremos a faca de serra e a tesoura para efetuar os cortes nas áreas demarcadas;

- Na figura 3, está a garrafa PET após os cortes, na garrafa foi feito 3 cortes o bico (1), o tronco (2) e por fim a base (3) da garrafa PET, esta que será descartada, so serão utilizadas as partes 1 e 2 ;

- Na figura 4, utilizando a fita adesiva, foi feito o encaixe na garrafa PET inteira, pegou o bico (1) e acoplou na base da garrafa PET inteira, e passou-se fita adesiva para fixar as partes, com o tronco (2) esta foi encaixado na parte do bucal da garrafa PE inteiro, na qual também se utilizou a fita adesiva para fixar as partes;

- Na figura 5, temos a confecção das 4 aletas, na qual tem papel fundamental no lançamento do foguete, pois será elas que darão equilíbrio aerodinâmico do foguete. Utilizou-se 4 aletas todas com a mesma medida uniforme, tendo um formato um triangulo retângulo, tendo seus catetos medindo $15 \mathrm{~cm} \times 10 \mathrm{~cm}$.

- $\quad \mathrm{Na}$ figura 6, mostra o foguete já finalizado, para incorporar as 4 aletas utilizou-se a fita adesiva para fixalas ao corpo do foguete seguindo uma distancia uniforme de uma aleta a outra.

Devem-se observar também alguns cuidados na montagem para garantir que o foguete tenha uma boa velocidade e aceleração na partida, o que podelevá-lo a grandes alturas. A imagem relata todo processo na elaboração do projeto ministrada com a turma do ensino, na confecção do foguete.
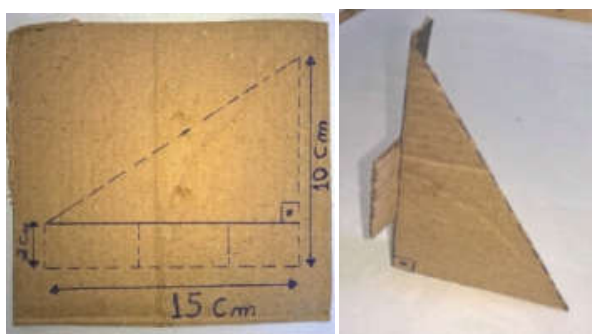

Fonte: Autoria, 2018.

Figura 4. Confecção das aletas (papelão)

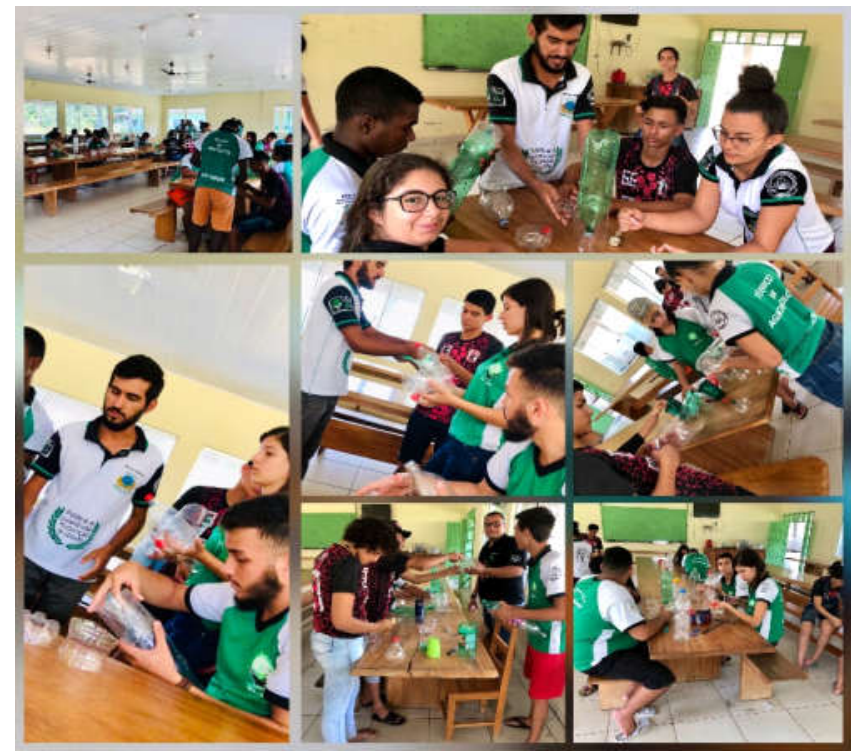

Fonte: Autoria, 2019.

Figura 5. Confecção do foguete pelos alunos, tendo auxílio do professor
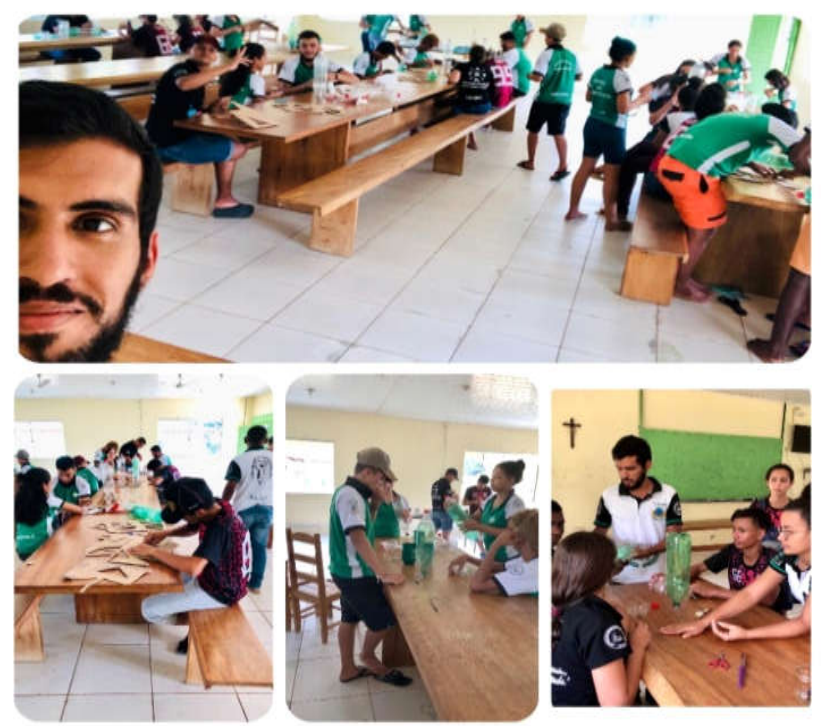

Fonte: Autoria, 2019.

Figura 6. Confecção do foguete pelos alunos, tendo auxílio do professor

Cálculos Das Variáveis Do Projeto: Para os cálculos utilizaram-se, como base os conceitos de Cinemática, tema este que foi tabalhado em sala com os alunos do primeiro ano do curso Técnico em Agroecologia integrado ao ensino médio da Escola Família Agrícola Dom Antonio Possamai EFADAP, onde os lançamentos dos foguetes serviram como suporte prático para demonstrar a teoria com a prática.

$1^{0}$ Passo: Dividir o tempo que foi cronometrado por 2, pois no movimento Oblíquo, temos o tempo de subida e o tempo de queda, considerando que os efeitos do ar são desprezíveis, o tempo da subida e o da queda são os mesmos, logo temos:

Tempo de Subida $=\frac{t}{2}$, onde $t$ é o tempo total cronometrado. (I)

$2^{\circ}$ Passo: A partir do resultado calculado na Equação (I) foi calculada a velocidade inicial que o foguete foi lançado, a partir da equação (II) no caso a equação da velocidade em função do tempo, com aceleração da gravidade no valor de $9,80665 \mathrm{~m} / \mathrm{s}^{2}$, no sentido contrário ao movimento. Com isso, o 
módulo da velocidade diminui com o tempo, caracterizando num movimento retardado, quando temos uma aceleração menor que 0 , e uma velocidade maior que 0 .

$V=V_{0}-g * t(\mathrm{II})$

A velocidade final será igual a 0 (zero) pois a equação de um projétil lançado no ar, é uma parábola, logo sua derivada é uma equação linear da velocidade, visto que a derivada (que determina a inclinação da parábola no plano cartesiano) resulta em 0 no ponto mais alto (RESNICK \& HALLIDAY, 1984), ou seja, essa velocidade é referente à quando o foguete atinge sua altura máxima e começa a descer, a velocidade que foi calculada na equação (II) será utilizada para determinar a altura máxima atingida pelo foguete e seu alcance máximo, formulas essas expostas no $3^{\circ}$ e $4^{\circ}$ passo.

$3^{\circ}$ Passo: Com base nos princípios de Galileu, para se calcular a altura máxima é preciso analisar o movimento vertical. Vejamos a função para se calcular a altura máxima:

$h_{\text {máx }}=\frac{V_{0}^{2} *(\operatorname{Sen} \alpha)^{2}}{2 g}$

$h_{\text {máx }}=$ altura máxima, $m$

$V_{0}=$ velocidade inicial, $\mathrm{m} / \mathrm{s}$

Sen $\alpha=$ Seno do ângulo $\alpha$

$g=$ aceleração gravitacional, $\mathrm{m} / \mathrm{s}^{2}$

$4^{0}$ Passo: Com base nos princípios de Galileu, o alcance horizontal é calculado, a partir da análise do movimento horizontal. Vejamos a função para se calcular o alcance horizontal:

$D=\frac{V_{0}^{2}}{g} * \operatorname{Sen} 2 \alpha$

$D=$ alcance máxima, $m$

$V_{0}=$ velocidade inicial, $\mathrm{m} / \mathrm{s}$

Sen $2 \alpha=$ Seno do ângulo $2 \alpha$

$g=$ aceleração gravitacional, $\mathrm{m} / \mathrm{s}^{2}$

Tabela 1. Testes tendo como combustível água e ar comprimido, ângulo da base de lançamento $60^{\circ}$

\begin{tabular}{|c|c|c|c|c|c|}
\hline \multicolumn{7}{|c|}{$\alpha=60^{\circ}$} \\
\hline Testes & $\begin{array}{c}\text { Tempo } \\
\text { Total (s) }\end{array}$ & $\begin{array}{c}\text { Tempo } \\
\text { de } \\
\text { Subida } \\
(\mathrm{s})\end{array}$ & $\begin{array}{c}\text { Velocidade } \\
\text { Inicial (m/s) }\end{array}$ & $\begin{array}{c}\text { Altura } \\
\text { Máxima } \\
(\mathrm{m})\end{array}$ & $\begin{array}{c}\text { Alcance } \\
\text { Máximo } \\
(\mathrm{m})\end{array}$ \\
\hline Teste 1 & 5 & 2,5 & 24,52 & 23 & 53,1 \\
\hline Teste 2 & 6 & 3 & 29,42 & 33,1 & 76,4 \\
\hline Teste 3 & 7 & 3,5 & 34,32 & 45 & 104 \\
\hline
\end{tabular}

Fonte: Autoria, 2019.

Tabela 2. Testes tendo como combustível água e ar comprimido, ângulo da base de lançamento $85^{\circ}$

\begin{tabular}{|c|c|c|c|c|c|}
\hline \multicolumn{7}{|c|}{$\alpha=85^{\circ}$} \\
\hline Testes & $\begin{array}{c}\text { Tempo } \\
\text { Total (s) }\end{array}$ & $\begin{array}{c}\text { Tempo de } \\
\text { Subida (s) }\end{array}$ & $\begin{array}{c}\text { Velocidade } \\
\text { Inicial (m/s) }\end{array}$ & $\begin{array}{c}\text { Altura } \\
\text { Máxima } \\
(\mathrm{m})\end{array}$ & $\begin{array}{c}\text { Alcance } \\
\text { Máximo } \\
(\mathrm{m})\end{array}$ \\
\hline Teste 1 & 7 & 3,5 & 34,32 & 59,58 & 20,85 \\
\hline Teste 2 & 6 & 3 & 29,42 & 43,8 & 15,33 \\
\hline Teste 3 & 6 & 3 & 29,42 & 43,8 & 15,33 \\
\hline
\end{tabular}

Fonte: Autoria, 2019.

As tabelas (1) e (2), são dados em relação aos foguetes que utilizaram como combustível para seu lançamento ar comprimido e água. Todos os foguetes teve inserido em seu interior na câmara de combustão a mesma quantidade de água $200 \mathrm{ml}$, utilizou-se para pressurização uma bomba de encher pneu de bicicleta com monômetro que indicava a pressão. Depois de acoplado o foguete na base, foi pressurizado até que atingisse $413.685 \mathrm{~Pa}$, após foi destravado a trava de segurança, desprendendo o foguete da base de lançamento.

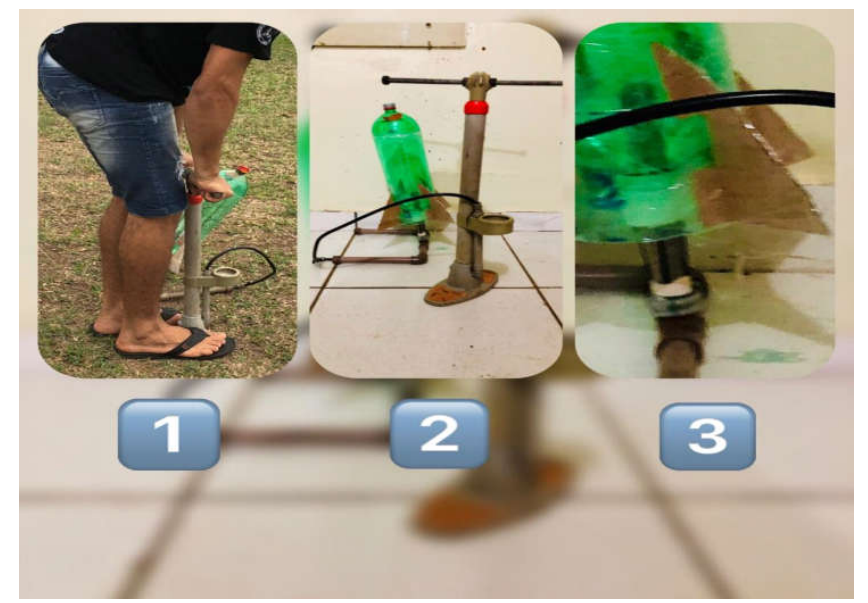

Fonte: Autoria, 2019

Figura 7. Foguete acoplado na base de lançamento, e sendo pressurizado utilizando a bomba de encher pneu (1) / esquema pronto para lançamento (2) / trava de segurança do foguete na base (3)

Tabela 3. Testes tendo como combustível a reação entre o Bicarbonato de Sódio e Acido Etanóico, ângulo da base de lançamento $45^{\circ}$

\begin{tabular}{|c|c|c|c|c|c|}
\hline \multicolumn{6}{|c|}{$\alpha=45^{\circ}$} \\
\hline Testes & $\begin{array}{c}\text { Tempo } \\
\text { Total (s) }\end{array}$ & $\begin{array}{c}\text { Tempo de } \\
\text { Subida (s) }\end{array}$ & $\begin{array}{c}\text { Velocidade } \\
\text { Inicial } \\
(\mathrm{m} / \mathrm{s})\end{array}$ & $\begin{array}{c}\text { Altura } \\
\text { Máxima } \\
(\mathrm{m})\end{array}$ & $\begin{array}{c}\text { Alcance } \\
\text { Máximo } \\
(\mathrm{m})\end{array}$ \\
\hline Teste 1 & 2 & 1 & 9,8 & 2,45 & 9,8 \\
\hline Teste 2 & 4 & 2 & 19,61 & 9,95 & 39,22 \\
\hline
\end{tabular}

Fonte: Autoria, 2019

A tabela (3), são dados com relação aos lançamentos dos foguetes por intermédio a reação química entre o Bicarbonato de Sódio e Acido Etanóico, foram feitos 2 testes, o teste (1) o tempo de espera da reação foi de 46 segundos antes de destravar o foguete da base para seu lançamento, no teste (2) o tempo foi de 155 segundos. Ressalto que a base não tem um monômetro que mede a pressão em seu interior, deste modo verificou-se pelo tempo de reação, fica evidente nos dados obtidos que o teste (2) teve um melhor desenvolvimento em sua reação, pois teve mais tempo para substancias se reagirem entre si, refletindo assim em dados melhores que o teste (1).

\section{RESULTADOS}

Em observação aos dados obtidos pelos lançamentos dos foguetes, utilizando bases com ângulos de $60^{\circ}$ e $85^{\circ}$ para os lançamentos utilizando água e ar comprimido como combustível, os lançamentos envolvendo a reação química utilizou-se base com ângulo de lançamento $45^{\circ}$. Conforme dito anteriormente, nos lançamentos a água e o ar são violentamente expulsos (ação) e empurrando (reação) a garrafa na mesma direção e sentido oposto se caracterizando na Terceira Lei de Newton. Em análise aos gráficosdas figuras 9 e 10 , analisando a altura máxima atingida pelo foguete, nota- se que os lançamentos envolvendo o ângulo de $85^{\circ}$ teve um 
melhor desempenho em relação aos com a base de $60^{\circ}$, porém se compararmos o alcance máximo atingido, os lançamentos com a base de $60^{\circ}$ teve um melhor desempenho em relação a de $85^{\circ}$.

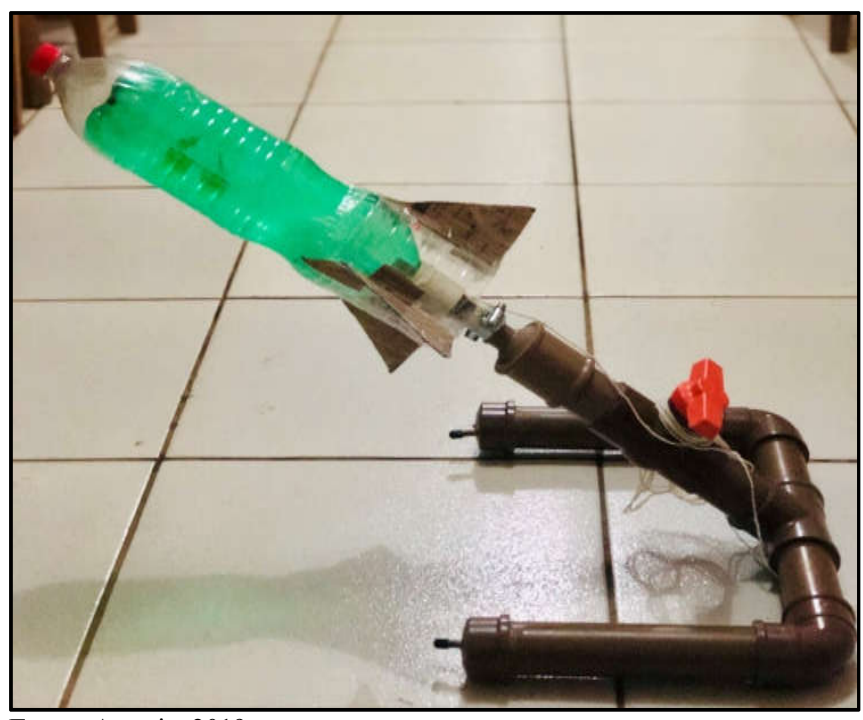

Fonte: Autoria, 2019.

Figura 8. Foguete acoplado na base de lançamento por Reação Química (Bicarbonato de Sódio e Acido Etanóico)

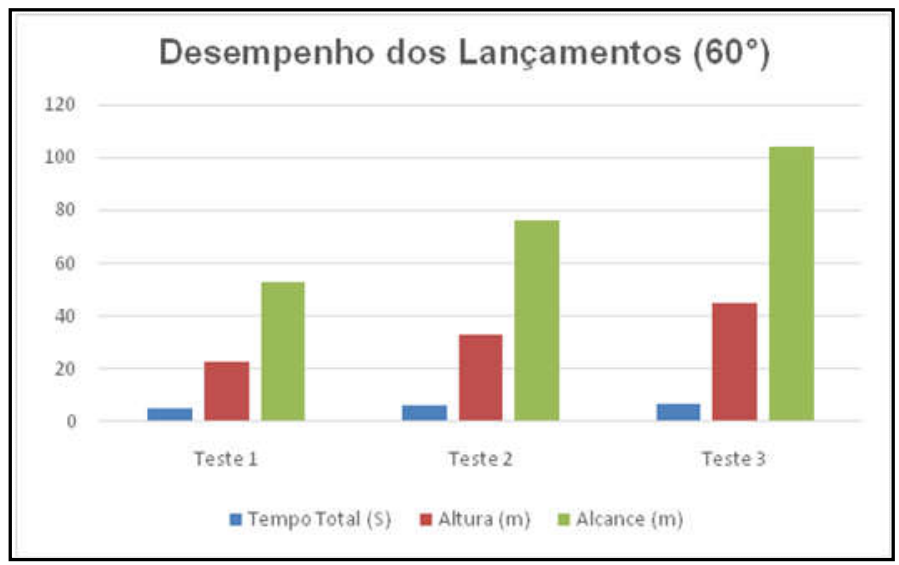

Fonte: Autoria, 2019.

Figura 9. Representação gráfica dos testes de lançamento do foguete, ângulo de $60^{\circ}$ (Água e ar comprimido)

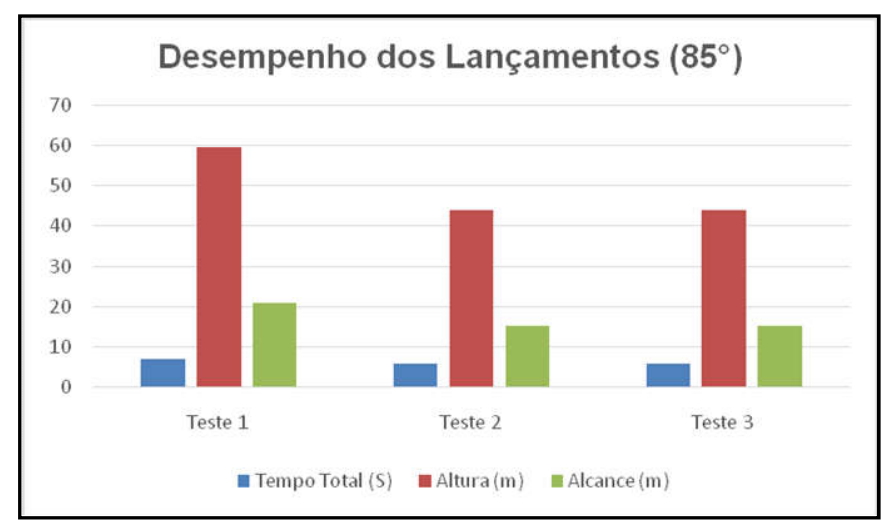

Fonte: Autoria, 2019.

Figura 10. Representação gráfica dos testes de lançamento do foguete, ângulo de $85^{\circ}$ (Água e ar comprimido)

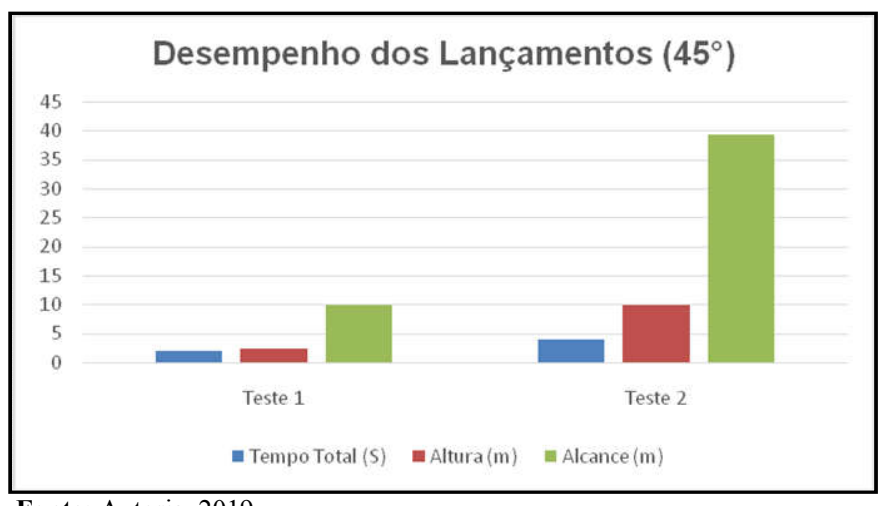

Fonte: Autoria, 2019

Figura 11. Representação gráfica dos testes de lançamento do foguete, ângulo de $45^{\circ}$ (Bicarbonato de Sódio e Acido Etanóico)

Tendo como análise a figura (11), na qual se trata de um gráfico do desempenho dos lançamentos com ângulo de $45^{\circ}$, na qual o alcance será máximo. Como o ângulo é multiplicado por dois na equação do alcance, o seno calculado será o de $90^{\circ}$, que corresponde ao máximo valor de seno possível, assim o alcance será o máximo possível. Analisando os dados do gráfico da figura (11), foi feito dois testes, no teste 1 o tempo de reação do Bicarbonato de Sódio e Acido Etanóico foi de 46 segundos antes do lançamento, já no teste 2 foi de155 segundos, deste modo ficou evidente que o tempo de reação interferiu diretamente no desempenho dos lançamentos.

"A atividade proposta pelo docente Dânlei Preato foi bem agradável, descontraída e produtiva. Sendo uma experiência, de um feito novo e divertido para os educandos e se transformando em uma boa forma de ensinar”. (ALUNO 1, 2019).

"Para o educando foi uma experiencia boa, pois nunca tinha realizado uma aula desse modo, nunca teve conhecimento deste tipo de aula, mais foi de bom rendimento para o educando". (ALUNO 2, 2019).

"O experimento foi muito bom, pois aprendi mais, podíamos fazer assim sempre, pois ajuda na nossa aprendizagem, nuca tinha feito isso e adorei achei interessante fazer os foguetes já que não sabia fazer $e$ agora já sei”. (ALUNO 3, 2019).

"O lançamento dos foguetes foi de suma importância, pois nos ajudou a entender a terceira lei de Newton, não só na teoria, mas na prática também, que deixa o aluno mais animado e se envolve mais na aula". (ALUNO 4, 2019).

"A construção do foguete de garrafa PET foi um excelente trabalho, pois além de aprendermos o conteúdo, nos alunos trabalhamos em conjunto mesmo sendo um trabalho individual, uns ajudaram aos outros... Obrigada professor Dânlei por ter nos proporcionado esse momento de aprendizado!!!". (ALUNO 5, 2019).

"Gostei muito desta aula prática, pois aprendi da melhor maneira possível que para cada ação tem uma reação, além de ter presenciado o lançamento de todos os foguetes que foi um sucesso gostei muito. Espero ter mais aulas práticas semelhantes a essa". (ALUNO 6, 2019).

"Foi uma aula extraordinária, aprendemos muito sobre reações e sobre a montagem e lançamento dos foguetes". Aprender nem sempre é somente lendo e falando mais sim praticando. Ótima experiência nessa aula prática. (ALUNO 7, 2019). 
"As aulas de física sobre lançamento de foguetes foi de grande valia, pois mostra aos educandos a grande importância da terceira lei de Newton ação e reação, na qual utilizamos muito em nosso cotidiano e não sabemos distinguir suas funções”.'(ALUNO 8, 2019).

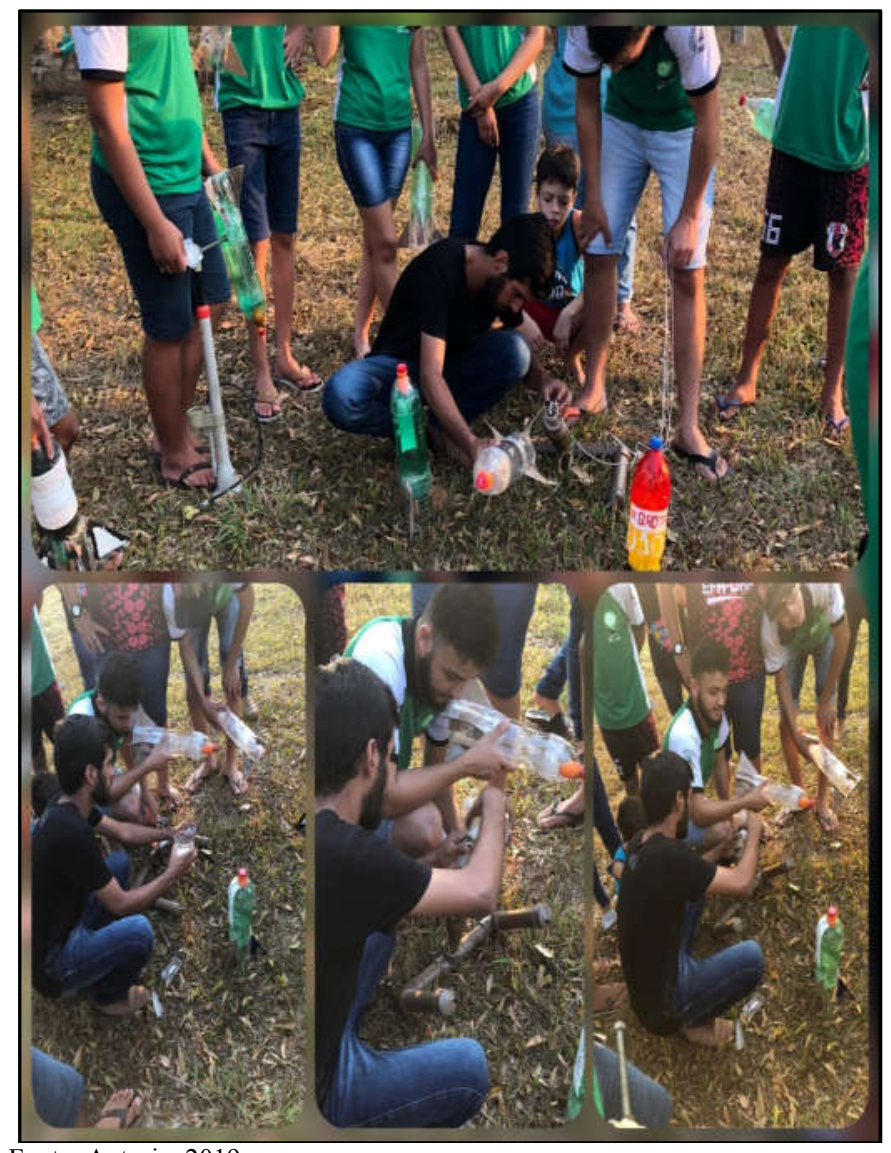

Fonte: Autoria, 2019

Figura 11. Preparando o lançamento do foguete, por meio da reação do Bicarbonato deÁcidoEtanóico

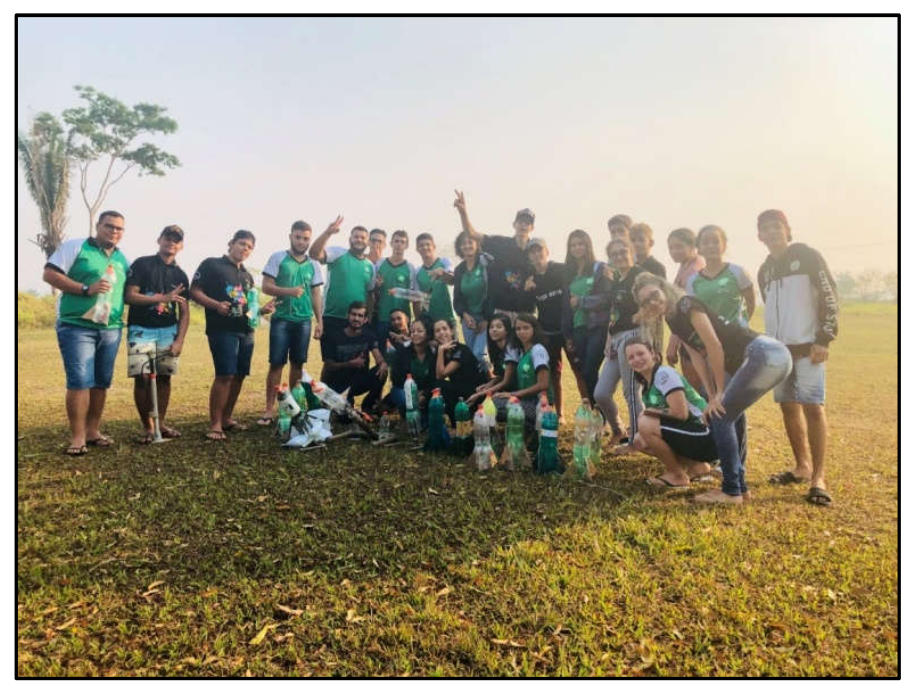

Fonte: Autoria, 2019.

Figura 12. Alunos do $1^{\circ}$ ano do Curso Técnico em Agroecologia Integrado ao Ensino Médio

\section{Conclusão}

Determinados resultados, apesarde justificados com equações e presunções simplificadas, não se enquadramperfeitamente com a realidade. À medida que o foguete sobe, ele perde água e pressão, tem atrito com o ar, entre outros fatores, para calcular esse movimento e conseguir a otimização da equação, deve-se utilizar decálculos aplicados na física e de algumas considerações, tornando o trabalhoum tanto complexo. Notase, como pôde ser observado nos comentários feitos pelos alunos, que a aula envolvendo experimentos se torna motivador, pois atrai o mesmo e o instiga em querer conhecer o novo, o aluno se sente desafiado. Infere-se a aplicação anual de projetos que necessitem da correlação das disciplinas lecionadas em conjunto com os conhecimentos adquiridos pelos alunos. Suscitando assim pessoas mais preparadas para as grandes adversidades do mundo globalizado atual.

\section{REFERÊNCIAS}

ABIB, M.L.V.S.; ARAÚJO, M.S.T. Atividades experimentais no ensino de física: diferentes enfoques, diferentes finalidades. Revista Brasileira de Ensino de Física, São Paulo, v.25, n.2, p.176-194, 2003.

Faça um foguete com garrafa PET. Disponél em: www.madscience.com.br. Acesso em 25/07/2018.

Foguete de garrafa PET. Disponível em: www.jornada.cba.ifmt.edu.br . Acesso em 26/07/2018.

GALILEU: O ombro gigante da Fisica. Scientific American Brasil: Gênios da Ciência. São Paulo, n. 1, 2. ed. Duetto.

HALLIDAY, David.; RESNICK, Robert; WALKER, J. Fundamentos de Física: Gravitação, Ondas e Termodinâmica. V. 2, 4. ed. Rio de Janeiro: LTC, 1984 (Livros Técnicos).

NUSSENSVEIG. Moisés H. Curso de Física Básica: Fluidos, Oscilações, Ondas e Calor. v. 2, 4. ed. São Paulo: Edgard Blücher, 2002.

Relatório de foguete movido a vinagre e bicarbonato de sódio. Disponível em: www.ebah.com.br. Acesso em 25/07/2018.

SARAIVA-NEVES, Margarida; CABALLERO, Concesca; MOREIRA, Marco Antônio. Repensando o Papel do Trabalho Experimental, na Aprendizagem da Física, em Sala de Aula - Um Estudo Exploratório. Investigações em Ensino de Ciências, Rio Grande do Sul, v. 11, n. 3, p. 383401, 2006.

SERÉ, Marie-Geneviève; COELHO, Suzana Maria; NUNES, Antônio Dias. O Papel da Experimentação no Ensino de Física. In: Caderno Brasileiro de Ensino de Física. Florianópolis/BRA. v. 20, n.1, p.31 42, 2003.

Sociedade Americana de Química. Disponível em: www.acs.org . Acesso em 25/07/2018.

Um foguete de garrafas PET. Disponível em: www.sbfisica.org.br. Acesso em 25/07/2018. 